\title{
CHALLENGES FOR HIGH TEMPERATURE MATERIALS IN THE NEW MILLENNIUM
}

\author{
R.E. Schafrik, Scott Walston ${ }^{1}$ \\ ${ }^{1} \mathrm{GE}$ Aviation, Cincinnati, $\mathrm{OH}$
}

Keywords: superalloy, material development, aero-propulsion, materials modeling

\begin{abstract}
Superalloys have contributed markedly to societal benefit. It is difficult to imagine the modern world without superalloys. These materials provide the backbone for many applications within key industries that include chemical and metallurgical processing, oil and gas extraction and refining, energy generation, and aerospace propulsion. Within this broad application space, arguably the highest visibility challenges tackled by these materials have arisen from the demand for large, efficient land-based power turbines and lightweight, highly durable aeronautical jet engines. So impressive has been the success of these materials that the last half of the $20^{\text {th }}$ century has been known as the Superalloy Age. While superalloys have met many technical challenges, the overarching consideration is that no use of these materials occurs unless value to the customer is demonstrated. This paper discusses the emerging paradigm within the aviation industry that applies customer requirements to drive materials development and implementation on an accelerated timeline. This new paradigm is first of all spurring on competition to materials from other technologies, and secondly opening the door to other material classes to compete with superalloys for key applications. The superalloy community has the opportunity to respond with innovative alloys and processing improvements. In the ideal case, this competition will result in the development of the best ideas, such that the end customer, whether a civilian or military aeronautical system operator, receives optimal value. This new development paradigm is leading to overall faster application of advanced materials.
\end{abstract}

\section{Introduction}

The customers for superalloy technology are many within the aero-propulsion community: the flying public, airline operators, national defense flight system operators, OEM engine manufacturers, and the superalloy manufacturing value chain. Requirements from these different customers establish the challenges for future desired capability, and consequently greatly influences superalloy development. In some cases, the effect of the superalloy industry on the customer is clear, such as eliminating manufacturing anomalies that lead to premature component failure and reduced engine time-on-wing. But other connections to the customer are not as obvious, such as reducing the usage of critical, strategic, rare elements. It is important for the superalloy industry to understand these relationships and their impact on the customer's operations in order for the entire industry to continue to succeed.

The materials science and engineering (MS\&E) community has been at the forefront of advancing our understanding of superalloy materials, and developing new generations of materials and processes in response to customer needs. In the past, it was not unusual for development programs to require up to 10 years, and sometimes longer, to complete R\&D and scale-up for production, bridging the "valley of death." Today, these long development times are difficult to sustain. Not only are they costly, but they introduce uncertainty since user requirements are not stagnant over such a long time period. The development timelines for new commercial engines is often within 3 years, so a 10-year materials and process development effort would have to target applications two generations beyond the current one, resulting in unclear requirements.

There continue to be many demands for improved high temperature materials to enable further advances in aeropropulsion technology. But customers are not wedded to superalloys; they are wedded to functionality. New material classes, such as intermetallics and ceramic materials, are challenging superalloys for key applications, particularly since the conventional wisdom is that superalloys are bumping up against their technical entitlement level.

The first step in targeting a material development effort to potential applications requires an understanding of the requirements of the many different users of superalloys.

\section{Customer Perspective}

The various customers for superalloy technology each have somewhat different priorities. To illustrate how the customer requirements relate to high temperature materials development, the scenario of a new commercial aircraft engine will be presented.

The economics of the commercial engine business is akin to the cell phone industry. The price to a customer (airline) for a new cell phone (engine) is often heavily discounted to minimize the up-front expenditure. Consequently, cell phone company (OEM engine manufacturer) profits on investments are not made until service contracts or spare part sales are realized in the future. Since the development and certification of a large commercial engine costs upwards of US\$1B, some engine programs will not show a positive return on investment for 10-15 years as illustrated in Figure 1. This economic model drives behavior of the airline customers and OEM engine manufacturers, and directly impacts the superalloy industry.

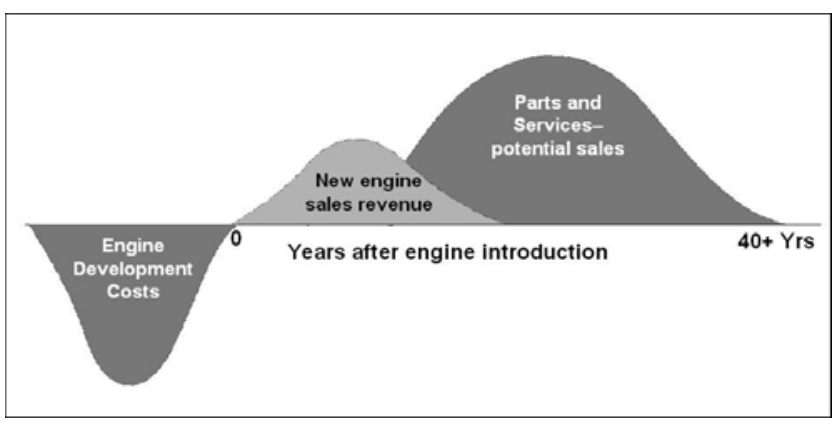

Fig. 1. Notional engine OEM business model 
For an airline, the cost of the engine represents a significant portion of the life cycle cost of the airplane. Initially, the engine represents about $20-25 \%$ of the aircraft price. Figure 2 shows the direct operating costs for a typical airline operating a Boeing 737800. [1] Although fuel costs are increasing, maintenance costs are still a significant fraction of overall costs.

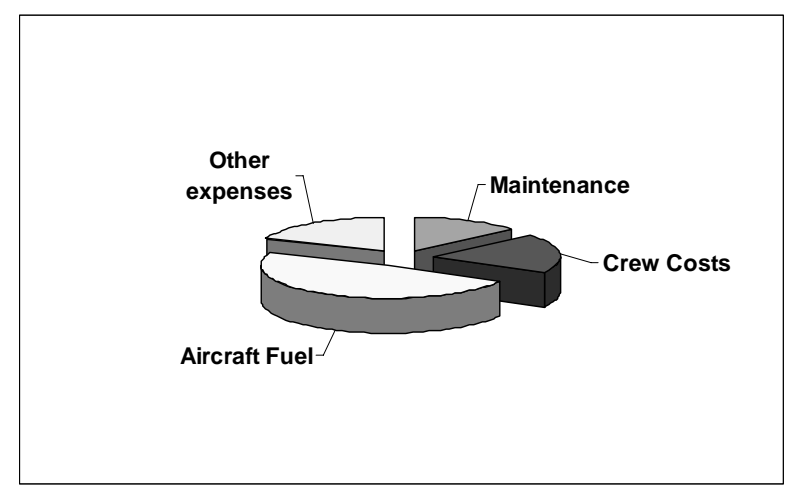

Fig. 2. Example of airline cost distribution

Figure 3 shows the distribution of Maintenance cost; note that the engine accounts for about $1 / 3$ of this cost element. These cost distributions are not consistent across the industry. Each airline has a unique cost structure governed by the age of its fleet, size of its aircraft, lease vs. buy arrangements, and its maintenance practices. For instance, those legacy carriers with older equipment will spend more for maintenance but may have lower lease costs/depreciation costs if its equipment is nearly paid for. But older airplanes are less fuel efficient, so fuel costs would be higher. Airlines with predominately new equipment will have proportionally lower maintenance and fuel costs, but higher leasing and depreciation expenses.

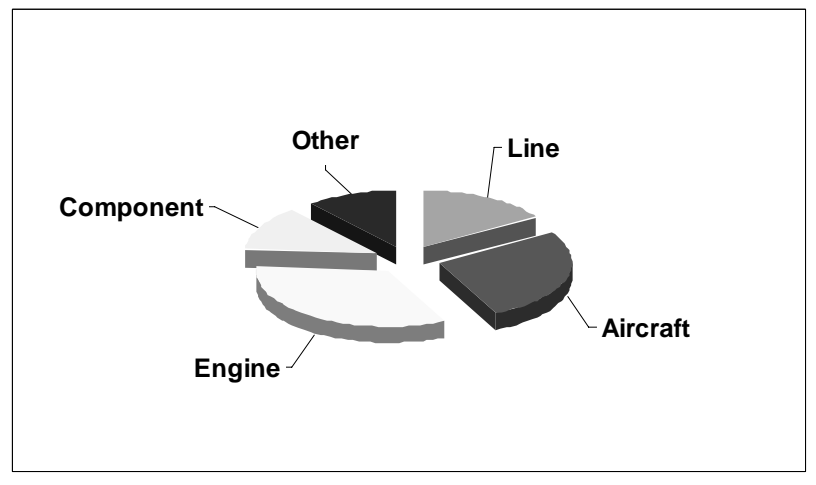

Fig. 3. Example of airline maintenance cost distribution

The initial price of an engine entering revenue passenger service can range up to US\$30M depending on complexity and thrust class. The costs of maintaining the engine over its lifetime can be 2-3 times the original price due to normal maintenance actions and shop visits. Since superalloys are used extensively in the portions of the engine that experience the most severe operating conditions, as well as for many life limited parts (usually limited by fatigue considerations), they have especially high visibility with respect to cost during shop visits. In fact, during a shop visit in which limited life parts (LLPs) are being replaced, the superalloy components can account for up to $60 \%$ of the total cost of the shop visit. This percentage is much higher than the cost of these parts relative to the cost of an entire new engine.

Maintenance cost is certainly a key driver in the commercial engine business, but reliability, safety and performance are even more important to the airline customers. The reliability of engines is the highest it has ever been, and in-flight-shutdown (IFSD) rates can be as low as 0.001 per 1000 flight hours for enginecaused events. This translates to 1 event for every 1 million engine flight hours, and of course, airplanes are designed to fly safely even in this condition (and most of the time, engines will restart). Certainly, the traveling public's expectation is for continued improvement in jet engine safety.

Competitive pressures have driven a relentless pursuit for improved fuel efficiency. The long term trend for reduced fuel consumption has averaged about $1 \%$ percent per year, due primarily to improvements in aerodynamic efficiency, combustor designs, and increased thermodynamic efficiency enabled by higher operating temperature materials.

Figure 4 depicts how customer requirements of cost, reliability and performance are flowed down to the superalloy industry. Beginning with the flying public, all of us seek the lowest possible price for a non-stop flight on an airline with a safe, reliable record. In response to this, airlines demand excellent reliability from an engine that meets performance specifications at a low life-cycle cost. This drives the engine OEM to develop a competitive engine that meets these requirements. During a recent engine sales campaign, a leading airline told the OEMs that, among other evaluation factors, each candidate engine offering would be judged against these metrics:

* Engine reliability

* Rate of engine deterioration

* Limited Life Parts guaranteed life

* Engine maintenance and repair work scopes tailored to the operating environment for each engine

* Availability of component repairs

\begin{tabular}{|c|c|c|c|}
\hline \multirow{2}{*}{ CUSTOMERS } & \multicolumn{3}{|c|}{ METRICS } \\
\hline & $\cos T$ & RELIABILITY & PERFORMANCE \\
\hline \multirow{5}{*}{$\begin{array}{l}\text { Flying Public } \\
\text { Airline } \\
\text { Powerplant } \\
\text { Engineering }\end{array}$} & Low ticket price & Safe flight & Non-stop flight \\
\hline & Good value & On-time arrival & $\begin{array}{l}\text { Pleasant } \\
\text { experience }\end{array}$ \\
\hline & $\begin{array}{l}\text { Low initial engine } \\
\text { price }\end{array}$ & $\begin{array}{l}\text { Excellent } \\
\text { reliability metrics }\end{array}$ & $\begin{array}{l}\text { Low fuel } \\
\text { consumption }\end{array}$ \\
\hline & $\begin{array}{l}\text { Low shop visit } \\
\text { cost }\end{array}$ & Long time on- & Low emissions \\
\hline & $\begin{array}{l}\text { Low on-wing } \\
\text { costs }\end{array}$ & & Long range \\
\hline 马 & $\begin{array}{l}\text { Low acquisition } \\
\text { cost }\end{array}$ & $\begin{array}{l}\text { Proven materials } \\
\text { capability }\end{array}$ & $\begin{array}{l}\text { Temperature } \\
\text { capability }\end{array}$ \\
\hline \multirow{3}{*}{$\begin{array}{c}\text { OEM Systems } \\
\text { Engineering } \\
\Omega\end{array}$} & $\begin{array}{l}\text { Low maintenance } \\
\text { cost }\end{array}$ & Defect-free processes & s Low weight \\
\hline & Repair availability & $\begin{array}{l}\text { Consistent properties } \\
\text { \& processes }\end{array}$ & $\begin{array}{l}\text { Low environmental } \\
\text { impact }\end{array}$ \\
\hline & $\begin{array}{l}\text { Low cost materials } \\
\text { High yield }\end{array}$ & $\begin{array}{l}\text { s Low material } \\
\text { property variation }\end{array}$ & $\begin{array}{l}\text { High temperature } \\
\text { strength }\end{array}$ \\
\hline \multirow{3}{*}{$\begin{array}{l}\text { Superalloy } \\
\text { Industry } \\
\text { Deliverables }\end{array}$} & & $\begin{array}{l}\text { Tight process control } \\
\text { Environmentally }\end{array}$ & $\begin{array}{l}\text { Lightweight } \\
\text { materials }\end{array}$ \\
\hline & $\begin{array}{l}\text { Durable, economic } \\
\text { repairs }\end{array}$ & ic resistant materials & Robust chemistry \\
\hline & & $\begin{array}{l}\text { Rigorous NDE } \\
\text { procedures }\end{array}$ & space \\
\hline
\end{tabular}

Fig. 4. Flow down of customer requirements into superalloy industry deliverables

These requirements directly translate to deliverables for the superalloy industry, whether it is the alloy developer, material supplier, repair engineer or process engineer. This integrated 
view of the customer's requirements provides visibility into how improved process control, a lower cost material, or a higher strength material can affect the customer.

To further illustrate the effect that superalloy industry actions can have on the customers, consider a few theoretical but plausible scenarios:

* During the casting process of a single crystal turbine blade, a ceramic core shift results in an under-minimum wall thickness in the shank region of one blade. This weakened region was not detected at $\mathrm{x}$-ray inspection, and the blade entered service. After 10,000 engine flight cycles, this high pressure turbine blade failed, causing severe damage to the high pressure turbine and low pressure turbine sections of the engine. The passengers felt severe vibrations before the pilot shutdown the engine. The airplane landed safely at the closest airport, which was not its destination. The damage to a large engine could readily exceed several million dollars.

* After being introduced into service, it is determined that a new structural superalloy cannot be welded to yield a satisfactory repair. This results in an unanticipated cost to the airline of US\$200,000 to replace, rather than repair, the structural component. For a worldwide engine fleet of 5,000 engines, the total cost of this material "surprise" to the airline operators would be US\$1 billion.

* During alloy development of a new turbine blade alloy, laboratory oxidation testing demonstrated that the alloy met the stringent requirements for the new engine. But four years later, it is discovered that oxidation behavior in the field is significantly worse than estimated by the laboratory tests, leading to the eventual removal of turbine blades 6,000 cycles before the engine was scheduled for shop visit. This would disrupt customers' logistical systems, and could lead to engine OEM warrantee payments to them as compensation for lost time-on-wing.

* The elemental cost of cobalt, tantalum, rhenium (take your pick!) has increased more than $100 \%$ during the past 18 months, and delivery of some of these elements could not be guaranteed in the longer term due to their short supply. Alloy developers using advanced alloy modelling and simulation techniques could quickly react with new alloy chemistries possessing equivalent properties with reduced content of these elements. Introduction to the fleet well ahead of historical schedules (1/2 the historical time) would avoid disruption of part deliveries and save customers millions of dollars.

The point of these examples is that seemingly small steps in the development or processing of superalloys can have dramatic effects on the customer downstream. Identifying and achieving the right requirements during the alloy, process or repair development stages is crucial to the future success of the superalloy industry's customers.

The above discussion of customer requirements leaves out one key reality. Success in the commercial and military aircraft engine business is largely dependent on having the right engine ready at the right time for a given aircraft application. Historically, the lead-time for a new engine program is usually less than the cycle-time for a new alloy development program. This has resulted in a production engine model that does not contain the very latest alloy or process, and thus is not as capable as it could have been made, disappointing customers.

\section{A Path to Acceleration Innovation}

The historical timeline for material development is lengthy, driven by the largely sequential and experimental nature of the work. However, product development timelines have continued to decrease. Overall, within the jet engine technology field, materials development has not kept pace with the accelerated timeline. However, there is an emerging paradigm that is guiding materials developers to faster completion of materials and process developments; it requires tight linkage between the materials and the systems engineering and design engineering communities, using the metric of "customer value" to steer the selection of technologies.

In the past, materials (and processes) were developed to be "better" than existing materials. The expectation was that applications for the improved material or process would be forthcoming. This approach succeeded for a number of years. Table 1 contains typical times that were required to fully develop and implement a new material for an aircraft engine application. Very few tools existed to help alloy developers design the chemistry of alloys. (An early exception was the development of models based on Linus Pauling's Electron Vacancy Theory that provided an estimate of the susceptibility of superalloy chemistries to deleterious TCP precipitation.) Therefore trial and error, with much testing, was the rule. For instance, General Electric's René 41 superalloy was so named because a usable alloy was discovered on the $41^{\text {st }}$ iteration after nearly a decade of research. A new class of structural material, intermetallic TiAl, required 30 years to complete development before it was used in the GEnx engine.

Table 1. Historical materials development timelines [2]

\begin{tabular}{|c|c|c|}
\hline CASE & ACTIVITY & TIME \\
\hline Case I & $\begin{array}{l}\text { Modification of an existing material for a } \\
\text { critical structural component }\end{array}$ & $2-3 \mathrm{yr}$ \\
\hline Case II & $\begin{array}{l}\text { Modification of an existing material for a } \\
\text { critical structural component }\end{array}$ & $\begin{array}{l}\text { up to } 4 \\
\text { yr }\end{array}$ \\
\hline \multirow[t]{2}{*}{ Case III } & $\begin{array}{l}\text { New material within an existing alloy } \\
\text { system }\end{array}$ & $\begin{array}{l}\text { up to } \\
10 \mathrm{yr}\end{array}$ \\
\hline & $\begin{array}{l}\text {-Includes time to define the chemistry and the } \\
\text { processing details } \\
\text { • Supply chain already exists }\end{array}$ & \\
\hline \multirow[t]{3}{*}{ Case IV } & $\begin{array}{l}\text { New material class with no prior } \\
\text { application experience }\end{array}$ & $20+y r$ \\
\hline & $\begin{array}{l}\text {-Includes the time to develop design practices } \\
\text { that fully exploit the performance of the new } \\
\text { material class }\end{array}$ & \\
\hline & •Establish supply chain & \\
\hline
\end{tabular}

Since such a long time was required for materials development, design engineers could not accurately foresee what material would be needed in 10 years; they were focused on engineering the next generation engine, not the generation afterwards. And often the materials developers were right in their assessments-they correctly anticipated the need for higher temperature capable superalloys. But they could not anticipate the specific property 
requirements, leaving designers the alternatives of (a) working around certain shortfalls of a new alloy or process with the suspicion that more "surprises" were lurking, or (b) accommodating the known deficiencies of an older material. Needless-to-say, often they chose the latter option, considering it to be lower risk.

While materials developers continued along this Edisonian path, other disciplines, such as aerodynamics and mechanical engineering, were making significant strides in computer modeling. Finite element modeling, computational fluid dynamics and heat transfer analysis, to name a few design technologies, were increasingly able to perform design iterations by computer analysis rather than building subscale models and measuring data. For instance, the new composite fan blade shape for the GE90-115B was designed using 3D aero code in 72 iterations over the course of a few weeks. If that work followed the historical materials development paradigm, 72 subscale models would have had to been built and tested in a wind tunnel over the course of several years at great expense. Thus it is not surprising that new engine programs are completed within 36 months, with 24 months as a goal, while materials development often requires several times this length.

In essence, design technology had out-paced materials development technology. Also, design tools now demand more material behavior data throughout the temperature range and stress range of interest to determine if a given material can satisfactorily perform in a targeted application. Typical property data needs include: elastic constants, creep and stress rupture, yield and ultimate tensile strength, ductility, strain-rate sensitivity, high cycle and low cycle fatigue behavior, fracture toughness, impact resistance, and crack growth rate. But obtaining this data for multiple new candidate alloys can be an expensive, time consuming process, further adding to the bias in favor of using known alloys.

Achieving the appropriate balance in properties for an application is essential, but this has been challenging to accomplish using the Edisonian approach. For instance, analysis must be done to assess producibility even though the mechanical and physical properties may be satisfactory. This requires knowledge of the multicomponent phase diagram, recrystalization temperature, machinability, weldability, forgeability, and so on. Since significant resources must be expended to collect the required data, the cost and time risk has been high.

Engine developers will only invest in those technologies that will deliver the greatest system benefit. Therefore, material developers must compete for resources among all the different available technology opportunities. This competition occurs at two levels:

* Materials R\&D competes for funding priority with other technology areas, such as: acoustics, aerodynamics, combustion science, design technology, and heat transfer.

* Various material solutions compete among themselves in a quest to offer the best alternative to the baseline technology.

In essence, a materials solution must have a credible "value case." The costs of development and implementation need to compare favorably to the expected benefit for an application. This paradigm is significantly different than the historic approach, which was materials developer centric. This new paradigm is system engineering centric, requiring that proposed materials capability be aligned to design requirements that are derived from customer needs. In order for materials to compete effectively, interaction with engine systems and design engineers, and the supply chain must be appreciably increased, and development timelines compressed.

This process is illustrated in Figure 5. The top portion depicts the stages of materials technology creation; the bottom half depicts the stages of engine development and qualification. For technology creation, the investment is typically on the order of US\$1 million to establish feasibility. In this example, feasibility is achieved at Technical Tollgate 3, or TTG3. These technical tollgates are analogous to NASA's Technology Readiness Levels, or TRLs, plus they also incorporate manufacturing maturity considerations. The investment cost in technology increases approximately by an order of magnitude to demonstrate capability (TT6), and can increase by another order of magnitude to mature the technology (TTG9) since required supply chain investment costs alone can be on the order of US\$100 million unless the existing industrial can be sourced.

Under this new paradigm, materials developers exercise creativity in conceiving and establishing the feasibility of a new material. But a major difference is that feasibility is determined with respect to a particular set of design-based requirements, rather than to a generic set of needs devised by the developers themselves.

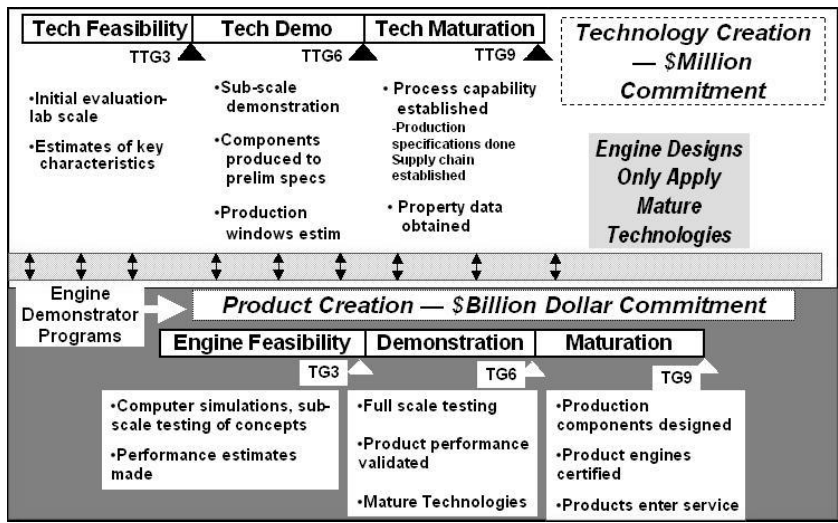

Fig. 5. Material technology and product development stages and interaction

Engine demonstrator platforms are often used to validate various technologies, such as a high efficiency compressor design or a new turbine blade material, before a formal new engine is launched at Tollgate 6 (TG6). These platforms explore the realm of the possible, without being constrained to meet specific requirements. Once a decision is made to launch the engine however, specific criteria are established that the engine must meet. The product creation process has 3 key development stages, each of which is defined by a tollgate process that measures progress toward the set of requirements: determine feasibility (TG3), demonstrate product capability (TG6), and mature the product for entry into service (TG9). The cost to create a new centerline engine can be US\$1 to $\$ 2$ billion, or more, to proceed through to TG9. The 2 to 3 year accelerated engine development timeline usually refers to the time between TG6 and TG9; the time between TG3 and TG6 can be much less than a year. 
Ideally, a technology targeted at an application in the engine will be at TTG9 when the engine development program is at TG6. This allows the timeline between TG6 and TG9 to shrink, with 24 months the goal since mature technology can be inserted with a minimum of unplanned, costly surprises. Of course, there is ongoing communication much earlier than TG6 between the materials development efforts and the engine development program. This interaction is important to insure that the materials effort continues to be targeted at the right application(s), the appropriate validation tests have been done, the required design practices are being developed, appropriate scalability and processability issues are understood, and inspectability methods are well-defined.

As the technology and product development programs progress in parallel, better definition of costs and benefits of the technology can be made, reinforcing the business case. This is important not only for the technologist, but also for the supplier base that requires lead-time to develop their business cases to industrialize a new technology.

The material development process is complicated by the fact that within the materials field, various material approaches vie for development resources. Nickel superalloys are the baseline technology, but are being challenged on the lower temperature end by intermetallic titanium aluminides, and on the high temperature end by ceramic matrix composite (CMC) materials and refractory metal intermetallics, such as niobium silicides.

From an engine design engineer perspective, material options are desirable since that increases the opportunity to achieve the best match of material properties to design requirements. From a material developer viewpoint, the opportunity to present a leading edge idea as a candidate to satisfy a defined need is rewarding. This competitive approach opens the door to new ideas, and overcomes inertia and stagnation in materials technology. For example, superalloy airfoils are well established in the turbine section of the engine. But great strides are being made in the development of ceramic matrix composite airfoils; the feasibility of using CMCs in this application is currently being established. Superalloy airfoil developers are responding to this challenge by an innovative initiative that includes simultaneous advancement in airfoil substrate materials, heat transfer technology, and airfoil coatings to provide a turbine blade with capability for substantially longer operation at higher temperatures. Thus, competition between these material systems has led to advancements across a broad front.

The grand challenge for materials development is to drastically reduce the development time for new materials and processes without adding development risk. The superalloy development sequence used during the past 50 years could be characterized, for the most part, as sequential. New materials were invented, and then a long process ensued to find a specific application, tweak the alloy and processing as necessary, fill in all the other required details and establish the supply chain.

The new accelerated development paradigm avoids many of the pitfalls of the past, using integrated teams that employ analysis tools that include materials and process modeling combined with design of critical experiments. Materials modeling tools that effectively integrate heuristic and fundamental knowledge can provide realistic estimates of material properties, contributing an important element in the quest to address the grand challenge. Quantifying the future benefits of modeling can be difficult since most forecasts are based on an intuitive linear extrapolation of capability. But it is likely that the benefits become exponential once a critical mass of capability is attained, such as the leap aerodynamists made in designing airfoils once they had 3D aerodynamic tools.

For example, in order to develop a new material for a turbine disk application, a number of different models must be linked together to provide an estimate of material properties. The suite of tools include processing models (forging and heat treatment as a minimum), structure models (grain growth; precipitate kinetics, morphology and distribution; etc.), and property models (tensile, creep, and cyclic behavior at various temperatures.) The success of these models depend, in turn, on accurate knowledge (databases) of the multi-component phase diagram for the chemistry of interest, diffusion rates for the various constituents, boundary conditions for the forging process, and so on. If all of these tools were available and integrated, virtual materials could be used to design a virtual disk, and the results could readily be iterated to refine the requirements that the material should meet. The results of these analyses would then be used to define the disk material chemistry and its processing route. Subsequent targeted experiments would then verify the results of this modeling and simulation. The end result would be much faster materials development executed with much lower risk than is current standard practice.

The evolving development method is summarized in Figure 6. This approach is resulting in a reasonable reduction in development time and resources compared to the linear, sequential approach. Using this latest methodology, the business case for materials technology is firmly established with the aid of the system engineers for a particular application together with producibility experts.

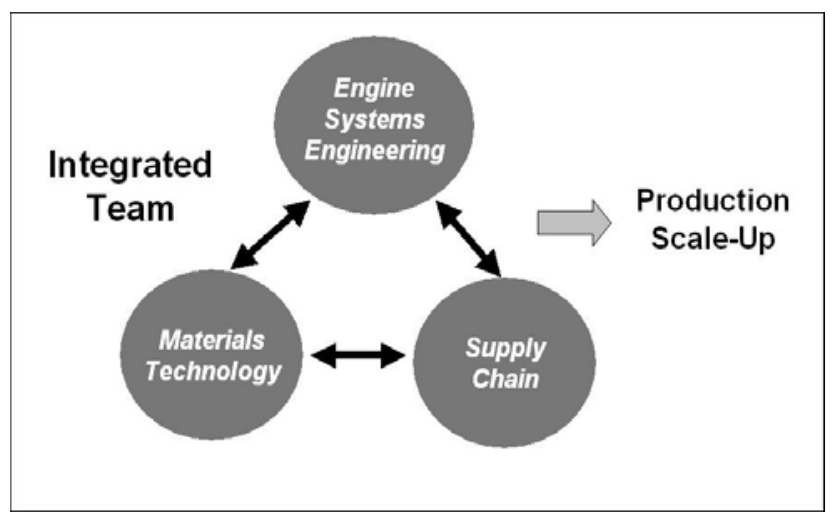

Fig. 6. State-of-the-art development practice

In the case of developing a new material or process that requires substantial supply chain investment, it may be worthwhile to form a consortium comprised those OEMs who would be likely customers for the technology. If pursued to the pre-competitive feasibility stage, the supply base would have a firmer basis upon which to make their investment decisions. In addition, the robustness of the technology would likely be greater since it would have been developed to serve multiple applications. [3] 
The first phase of the development program is typically constructed to demonstrate feasibility of the technology for the application. Once this has been accomplished, components are made and tested. Usually some further optimization is necessary to improve certain properties, improve producibility, reduce cost, etc. Finally, production scale-up occurs after the material is specified for use.

Progress in accelerating materials development, at this point in time, is not as rapid as it could be since the teams are not fully integrated for reasons that include:

* The tools that are being used across the teams are not fully functional, are not standardized, and/or not fully linked together. For instance the development of new design practices required to fully exploit new material capability might be delayed if new design tools must first be developed and qualified. [4]

* Legal issues regarding contractual terms and conditions, such as protection of proprietary data, retard progress for team members that are not part of the company leading the development effort. A complicating factor is that these team members can also be competitors on other projects, and thus there is an understandable reluctance to share best ideas.

* Different reward structures exist among industry, university, and government laboratory team members. This results in differing priorities that can affect timely completion of critical tasks.

* Intra-company team members may work at different paces, owing to their organizational priorities. For instance, development of new design practices may lag materials development, producibility may not be evaluated in a timely way, etc.

\section{Development Opportunities}

The framework described above provides a path for implementing new materials technology, transitioning it from the laboratory into a production engine in one-half or less of the traditional timeline. A solid value case is essential to obtaining the necessary business support for the development program at both the OEM and the supply base. The crux is identifying and evaluating the suite of top-notch ideas that will further advance high temperature structural materials since materials must first of all compete with other technologies for resources. As we look into the future, some of the M\&P opportunities lie in the following areas:

* Materials modeling and simulation tools need to be further advanced to incorporate fundamental materials science knowledge, fully exploiting the rapid increase in desktop computing capability. In particular, significant opportunity exists to develop multi-scale and multi-physics modeling and simulation tools that encompass computational modeling of material systems at multiple spatial and temporal scales. These tools could be capable of estimating the effect of subjecting a material to multiple physical stimuli (mechanical, thermal, chemical, etc.), offering the promise of designing new materials and processes that will meet requirements based in large measure on computer analyses. [5]

* Determine the fundamental material property entitlement level for a material or process, and tackle the impediments preventing full entitlement. For example, the gap between average properties and the minus-3-sigma properties can be quite large. Since design engineers employ minus-threesigma properties, any improvement in processing that reduces the scatter in creep and fatigue properties would result in an immediate benefit.

* Environmental and thermal barrier coatings are essential to providing added capability, allowing high temperature materials to remain in service longer in severe environments. Rather than developing these coatings sequentially, they could be developed in concert with the underlying structural material so that chemical and mechanical compatibility exists.

* Materials can be processed so that the microstructure is tailored to optimize the properties location-by-location, versus the standard practice of striving for homogeneous properties. An example is a dual property turbine disk, in which the rim has coarse grains to provide better creep properties, while the bore is fine-grained to optimize fatigue life. The properties of the grain transition zone would also have to be well understood.

* Composite, hybrid, and multifunctional materials can provide additional degrees of freedom for the design engineer to meet customer requirements, enabling engineered, optimized structures. An example, extending the idea of a dual-property disk, would be to use a different material for the rim of a disk than for the bore; or a compressor blade that would have an impact-resistant leading edge attached to a toughened blade material.

* Develop new processing routes that avoid altogether the limitations of current processing routes. For instance, powder metallurgy and iso-thermal forging enabled the manufacture of high strength turbine disks by overcoming the limitations of cast and wrought metallurgy. Direct deposition methods have the potential to be a significant processing game changer.

* In order to better gauge the in-service degradation of materials, prognosis will likely become pervasive in turbine engines. Further development of in-situ sensors attached to analyzers would allow better estimates of the extent of material life degradation during in-service operation. In this regard, multifunctional materials could be employed, such as a coating that performs its intended function while also reporting the extent of coating degradation.

* Advanced intermetallics, such as those based on silicides, hold promise to supplant superalloys for some key turbine components, such as shrouds, nozzles, and blades. But developing a new material system is a significant undertaking, and its acceleration requires a concerted effort by multiple partners, possibly across national boundaries, and encompassing industry, universities, and government laboratories, in order to demonstrate pre-competitive feasibility. Such an effort might include business agreements in addition to technology advancement.

* Current laboratory tests of advanced materials do not adequately simulate jet engine operating conditions. This is particularly true of high temperature testing in extreme environments. For example testing that incorporates multiple degradation modes simultaneously, such as creep, fatigue, and environmental attack would be particularly useful. 


\section{Summary}

The first 60 years of jet-powered flight has been quite exciting, far exceeding expectations of most "experts" from the earlier eras. Materials and process advancements have played a key role in this adventure. The next 60 years of jet engines is sure to be as equally exciting, and there can be little doubt that progress in materials and processes will be pacing the advancements.

Superalloy customers are demanding faster development cycles, more reliable materials with less variation and lower cost approaches. These customer requirements present the Grand Challenge to the materials development community of doing our work "better, faster, cheaper." In order to meet this challenge, a new materials development method is needed, which includes:

* A system engineering centric paradigm, requiring that proposed materials capability be aligned to design requirements, and critical-to-success metrics identified that can focus resources to assure implementation success. This necessitates tight linkage between materials technologists, the engineering design community, and the supply chain, and lastly applying the metric of customer value to guide the final selection of the technologies.

* Under this new paradigm, materials developers establish the feasibility of a new material. However feasibility is determined with respect to defined needs of a particular component, rather than to a generic set of requirements posited by the material developers. These needs include prediction of component behavior with respect to all possible material degradation modes in the anticipated service environment, and consideration of the effect of process variation and cost for production scale-up.

* Materials modeling and simulation are essential tools. Material innovation requires exploring multiple paths to find the optimum solution. Laborious physical trial-and-error experiments, aimed at finding the appropriate solution, are too lengthily and costly to be the primary method of investigation. Computer-based analyses, followed by targeted physical experiments, can quickly and efficiently determine technical feasibility and guide the scale-up effort for the desired materials solution.

The past success of high temperature alloys, and superalloys in particular, is unimpeachable. Looking forward, there remain many outstanding opportunities for further contributions by these materials to advance aero-turbine technology. Beyond jet engines, a similar value case for advancing superalloy technology can be made in other application domains.

\section{References}

[1] “Aircraft Operating Costs and Statistics for 2006," Aviation Daily, (New York, NY: Aviation Week, McGraw Hill Publishing, 21 June 2007), 19

[2] Accelerating Technology Transition: Bridging the Valley of Death for Materials and Processes in Defense Systems, (Washington, DC: National Academy Press, 2004), 16

[3] R.E. Schafrik; L. Christodoulou; and J.C. Williams, "Collaboration Is an Essential Part of Materials Development", JOM, 57, (3) (2005), 14-16

[4] J.C. Williams, "Progress in Aero-Propulsion-The Role of Materials”, private communication with author, Ohio State University, June 2003

[5] Decadal Survey of Civil Aeronautics: Foundation for the Future, (Washington, DC: National Academy Press, 2006), 130 